\title{
Microstructure and texture evolution of a high manganese TWIP steel during cryo-rolling
}

\author{
M. Klimova ${ }^{a}$, , S. Zherebtsov ${ }^{a}$, N. Stepanov ${ }^{a}$, G. Salishchev ${ }^{a}$, C. Haase ${ }^{b, c}$, D.A. Molodov \\ a Belgorod State University, Pobeda 85, Belgorod 308015, Russia \\ b Institute of Physical Metallurgy and Metal Physics, RWTH Aachen University, Aachen 52056, Germany \\ ${ }^{\mathrm{c}}$ Department of Ferrous Metallurgy, RWTH Aachen University, Aachen 52072, Germany
}

\section{A R T I C L E I N F O}

\section{Keywords:}

TWIP steel

Twinning

Martensite

Microstructure

Texture

Mechanical properties

\begin{abstract}
A B S T R A C T
The influence of rolling at $77 \mathrm{~K}$ and $293 \mathrm{~K}$ to a true strain of 2.66 on the microstructure and texture evolution and mechanical behavior of a TWIP Fe-0.3C-23Mn-1.5Al steel was quantified. The microstructure evolution at both temperatures of deformation was associated with an increase in the dislocation density and extensive twinning, following by the development of a cell structure and shear bands. Rolling at both temperatures was associated with a formation of the Copper-type texture in the beginning of deformation and transition to the Brass-type texture during further rolling. Intensive formation of $\varepsilon$-martensite was observed at $77 \mathrm{~K}$. The transformation of twin boundaries into arbitrary high-angle grain boundaries due to interaction with lattice dislocations led to the formation of grains/subgrains with the size of 30-60 nm after cryo-rolling to a strain of 2.66 . Rolling at both temperatures resulted in continuous increase of strength of the steel and decrease of ductility. The ultimate tensile strength was $1993 \mathrm{MPa}$ and $1824 \mathrm{MPa}$ after rolling to a true thickness strain of 2.66 at $77 \mathrm{~K}$ and $293 \mathrm{~K}$, respectively. Qualitative analysis of contributions of different strengthening mechanisms was performed.
\end{abstract}

\section{Introduction}

High manganese steels seem to be one of the most attractive materials for structural applications in the automotive industry due to their unique combination of strength and elongation. The mechanical behavior and the strain hardening of these steels largely depend on the stacking fault energy (SFE). In steels with SFE values in the range of about 20 to $40 \mathrm{~mJ} / \mathrm{m}^{2}$, the main deformation mechanism is mechanical twinning, which increases the uniform elongation due to a phenomenon known as the twinning-induced plasticity (TWIP) effect $[1,2]$. In addition, deformation-induced twin boundaries gradually reduce the effective glide distance of lattice dislocations, thereby increasing the strength (so-called "dynamical Hall-Petch effect") [3].

One of the main disadvantages of TWIP steels is their relatively low yield stress, which limits their application in the recrystallized condition. The yield stress can be increased by various methods, such as precipitation hardening [4-7], grain refinement due to recrystallization $[8,9]$, or pre-straining [10-13]. Another way to increase the strength of TWIP steels is obtaining fine- or ultrafine-grained microstructures by plastic deformation $[14,15]$.

Microstructure refinement in metallic materials via large (or severe) deformation has been of great interest in the last decades. It was recently shown with respect to commercially pure titanium [16] that the kinetics of ultrafine structure formation during deformation is sensitive to the activity of deformation twinning. Due to a different dependence of the critical resolved shear stress of twinning and slip on deformation temperature, the intensity of twinning can be increased by decreasing the deformation temperature. Some preliminary results have shown the positive effect of very low temperature of $77 \mathrm{~K}$ on the microstructure refinement in TWIP steel during large deformation [17]. However, further investigations in this direction for a better understanding of the correlation between deformation conditions and microstructure evolution are still needed.

In addition, the activation of different deformation mechanisms is known to have a strong influence on the development of the crystallographic texture during cold rolling. A Brass or alloy texture with a lower intensity of the copper texture component and an increased intensity of the Brass and Goss components are often observed in low-SFE metallic materials that deform by twinning $[18,19]$. A Brass-type texture development can also be attributed to microscopic shear band formation [20], which in turn intensifies with decreasing temperature. While the texture evolution during cold rolling of low-SFE materials is

\footnotetext{
* Corresponding author.

E-mail address: klimova_mv@bsu.edu.ru (M. Klimova).
} 
fairly well understood, there is much less clarity regarding deformation at cryogenic temperatures. Therefore, the aim of the present work was to quantify the influence of cryo-rolling to large strains at $77 \mathrm{~K}$ on the microstructure, texture evolution, and mechanical behavior of a Fe0.3C-23Mn-1.5Al TWIP steel.

\section{Material and Procedures}

A steel with a nominal chemical composition Fe-0.3C-23Mn-1.5Al (wt\%) was melted in an air conduction furnace and cast into a $30-\mathrm{kg}$ ingot (140 $\mathrm{mm}$ in height), followed by homogenization heat treatment at $1150{ }^{\circ} \mathrm{C}$ for $5 \mathrm{~h}$. The ingot was then forged to $50 \mathrm{~mm}$ thickness in 3 passes and annealed at $1150{ }^{\circ} \mathrm{C}$ for $4 \mathrm{~h}$. The forged plate was hot rolled at $1150{ }^{\circ} \mathrm{C}$ to $10 \mathrm{~mm}$ thickness and then annealed at the same temperature for $1 \mathrm{~h}$.

To determine the effect of strain and deformation temperature on the microstructure evolution, a $4 \mathrm{~mm}$ thick slab was rolled unidirectionally in few passes at room $(293 \mathrm{~K}$ ) and liquid nitrogen $(77 \mathrm{~K})$ temperature. A fixed rolling speed of $30 \mathrm{~mm} / \mathrm{s}$ was used. The following total true strains $\left(\varepsilon_{\mathrm{th}}\right)$ were achieved: 0.05 (engineering strain of $5 \%$ ), 0.07 (engineering strain of 7\%), $0.1(10 \%), 0.22(20 \%), 0.36(30 \%)$, $0.51(40 \%), 0.92(60 \%), 1.39(75 \%)$ and 2.66 (engineering strain of 93\%). Prior to cryo-rolling, each preform was encapsulated between sacrificial steel sheets, which were joined by spot welding. The pack was then cooled to $77 \mathrm{~K}$ in liquid nitrogen and rolled. The temperature of the canned work piece during such a pack-rolling process did not increase by $>20^{\circ} \mathrm{C}$. To ensure nearly isothermal deformation, each pack was cooled in liquid nitrogen between each rolling pass.

The microstructure in the mid-layer of the sheet specimens was characterized by means of transmission electron microscopy (TEM) using a JEOL JEM-2100FX and a Nova NanoSem scanning-electron microscope (SEM) equipped with back-scattered electron (BSE) detector and an electron-backscatter-diffraction (EBSD) camera. The SEM samples and TEM foils were electro-polished using an electrolyte composed of $10 \%$ perchloric acid and $90 \%$ acetic acid at a voltage of $20 \mathrm{~V}$ at room temperature. The step size during EBSD scanning was 0.2, 0.2 , and $0.15 \mu \mathrm{m}$ for the strain of $0.22,0.51$, and 0.92 respectively. The border between low-angle boundaries (LABs, shown with white lines on presented inverse pole figure (IPF) maps) and high-angle boundaries (HABs, shown with black lines) was assumed to be $15^{\circ}$. Misorientations below $2^{\circ}$ are not shown as boundaries. The points with confidence index (CI) below 0.1 were excluded from the analysis and are depicted as black dots on presented IPF maps. The misorientation angle among (sub)grains was analyzed by the conventional TEM Kikuchi-line method with a converged beam technique [21]. The dislocation density was estimated by counting the individual dislocations in the grains/subgrains interiors per unit area using at least five arbitrarily selected TEM images for each data point $[22,23]$.

In order to characterize the crystallographic texture, $\mathrm{X}$-ray pole figure measurements were performed by acquiring three incomplete $\left(0-85^{\circ}\right)$ pole figures $\{111\},\{200\}$, and $\{220\}$ at the specimen surface on a Bruker D8 Advance diffractometer, equipped with a HISTAR area detector, operating at $30 \mathrm{kV}$ and $25 \mathrm{~mA}$, using filtered iron radiation and polycapillary focusing optics. The corresponding orientation distribution functions (ODFs) were calculated using an algorithm of the MATLAB $^{\circledR}$-based toolbox MTEX [24,25]. The overall intensity of the textures was characterized by the respective texture index $T$ which was calculated as:

$T=\oint[f(g)]^{2} d g$

where $f(g)$ is the orientation density function and $g$ denotes the orientation defined by the three Euler angles $g=\left(\varphi_{1}, \Phi, \varphi_{2}\right)$. The ODFs for $\varphi_{2}=0^{\circ}$ and $\varphi_{2}=45^{\circ}$ are presented. The ODFs for $\varphi_{2}=65^{\circ}$ were not shown due to the presence of the single $S$ texture component and low informativity. The volume fraction of $\varepsilon$-martensite was determined

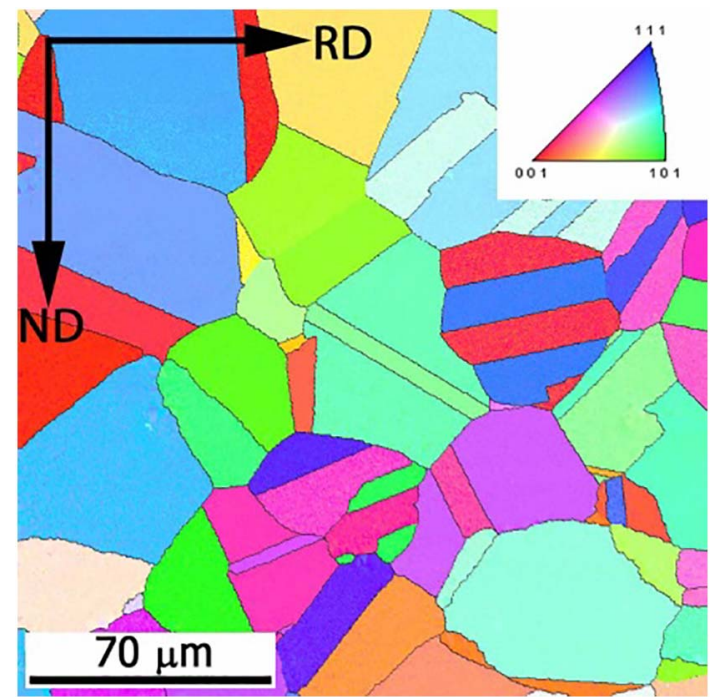

Fig. 1. EBSD map (IPF coloring with respect to the rolling direction (RD)) obtained on a specimen of the investigated steel in the initial condition (ND: normal direction). (For interpretation of the references to color in this figure legend, the reader is referred to the web version of this article.)

using the Rietveld method [26].

To determine the post-rolling mechanical properties, tension tests were conducted at room temperature. For this purpose, dog-boneshaped flat specimens with gauge dimensions of $16 \mathrm{~mm}$ length $\times 3 \mathrm{~mm}$ width $\times 1.5 \mathrm{~mm}$ (or smaller in case of large strain) thickness were machined and pulled to destruction at a constant crosshead speed of $1 \mathrm{~mm} / \mathrm{min}$ using a screw-driven test machine. The microhardness of the rolled specimens was examined using Vickers microhardness testing with a load of $0.2 \mathrm{~kg}$. At least 20 individual measurements per condition were made and the mean values are presented.

\section{Results}

\subsection{Microstructure Evolution}

In the initial state the microstructure of the material consisted of equiaxed austenite grains. Many grains contained annealing twins and essentially no internal substructure (Fig. 1). The mean grain size (taking into account the twin boundaries) was about $28 \mu \mathrm{m}$.

Microstructure response of the investigated steel on small strain during room temperature (RT) and cryogenic rolling was associated with deformation twinning (Fig. 2). According to SEM images, intensive twinning in the steel during cryo-rolling was observed at a true strain $\varepsilon_{\text {th }} \approx 0.05$ (Fig. 2b) while rolling at room temperature to $\varepsilon_{\text {th }} \approx 0.1$ resulted in twinning of some individual grains only (Fig. 2a).

At larger strains the microstructure evolution during rolling at both 293 and $77 \mathrm{~K}$ comprised elongation of grains, their further twinning, and the rotation of the twin-matrix lamellae towards the metal flow direction, as illustrated by EBSD IPF maps in Fig. 3. Since the minimum scanning step during EBSD measurements was comparable with the twins thickness, a majority of twins were missed. Nevertheless EBSD shows lower intensity of twinning at room temperature in comparison with that at $77 \mathrm{~K}$ at early $\left(\varepsilon_{\text {th }}=0.22\right.$ and 0.51$)$ stages of deformation (Fig. 3a, b vs. d, e) that most likely resulted in a pronounced difference in the microstructures at larger deformation. Rolling to a thickness strain of 0.92 at both temperatures resulted in the formation of a heterogeneous microstructure consisting of elongated grains with a variable density of twins and a developed substructure (Fig. 3c, f).

TEM investigation of the microstructural evolution during rolling (Figs. 4-6) confirmed the results obtained by SEM-BSE and EBSD. On the initial stages $\left(\varepsilon_{\text {th }}=0.07-0.22\right)$ of deformation at room temperature 


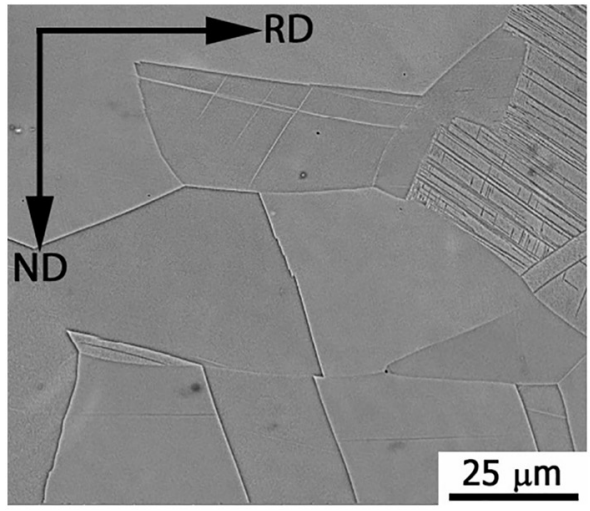

a

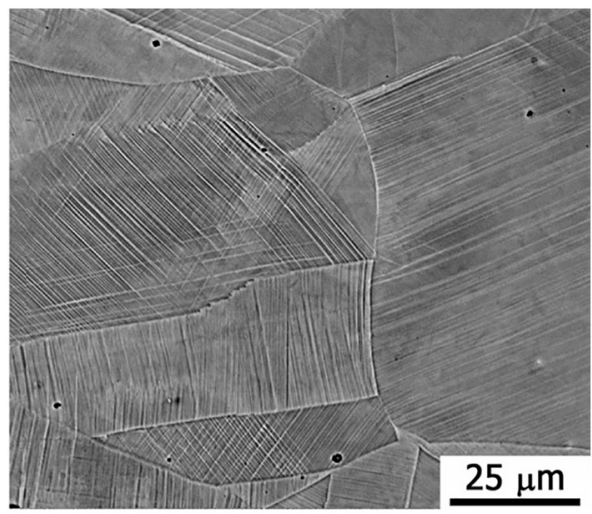

b
Fig. 2. SEM-BSE images of the Fe-0.3C-23Mn-1.5Al steel after rolling to a true strain $\varepsilon_{\text {th }}=0.1$ at $293 \mathrm{~K}$ (a) and $\varepsilon_{\mathrm{th}}=0.05$ at $77 \mathrm{~K}(\mathrm{~b})$. The images were obtained from the plane perpendicular to the transverse direction (TD). an increase in dislocation density (Fig. 8c) and the formation of dislocation pile-ups (Fig. 4a, b and insert in Fig. 4b) were observed. A few deformation twins are observed after rolling to $\varepsilon_{\text {th }}=0.22$ (Fig. 4b). Meanwhile similar strain levels at $77 \mathrm{~K}$ led to more intensive twinning and clustering of the parallel twins into bands of $\sim 500 \mathrm{~nm}$ width (Fig. 5a, b). At both temperatures the minimum thickness of twins was found to be $\sim 10 \mathrm{~nm}$; however, much thicker twins (or twin bundles) up to $300 \mathrm{~nm}$ were also observed. All examined twins belonged to the family (111) $\langle 112\rangle$ (twin/matrix misorientation of $60^{\circ}$ around a $\langle 111\rangle$ axis).

The main feature of the microstructure evolution of the $\mathrm{Fe}-0.3 \mathrm{C}$ -
23Mn-1.5Al TWIP steel during further rolling was a considerable increase in twin density. After RT rolling to $\varepsilon_{\text {th }}=0.92$ twins in some places entirely occupied the examined area; the formation of shear bands was observed at this stage of deformation (Fig. 4c). Twins can curve/bend during deformation due to mutual intersections or become stepwise (Fig. 4d). Further increase in dislocation density was also observed in addition to twinning (Fig. 8b). Similar processes were observed during cryo-rolling, however the kinetics of microstructure evolution was found to be noticeably faster in case of the lower temperature, i.e. occurred at lower strains. Therefore the microstructure formed in the cryo-rolled specimen after $\varepsilon_{\text {th }}=0.51$ (Fig. 5c, d) was

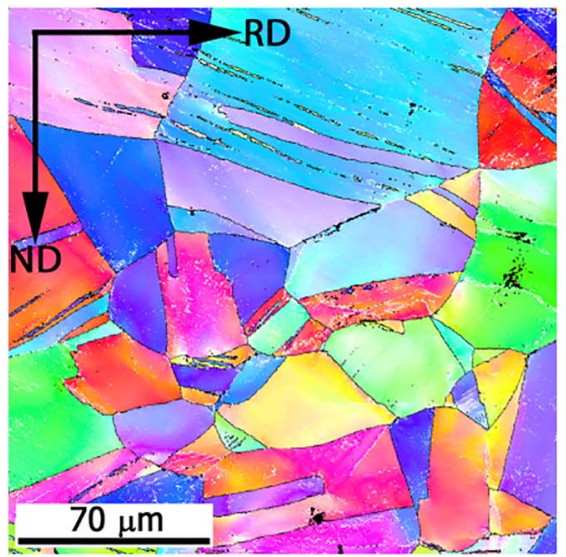

a

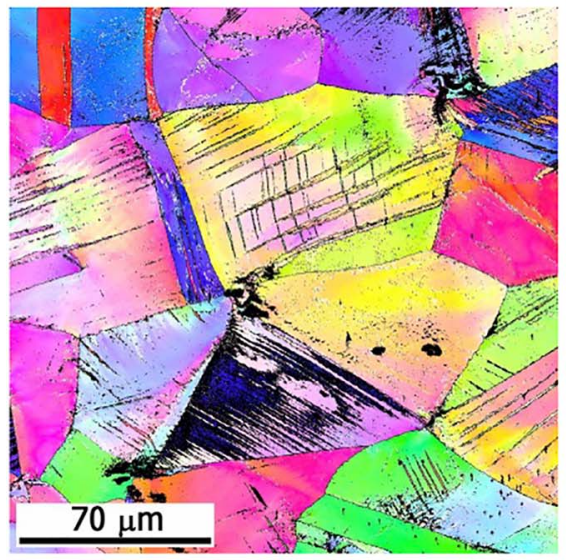

d

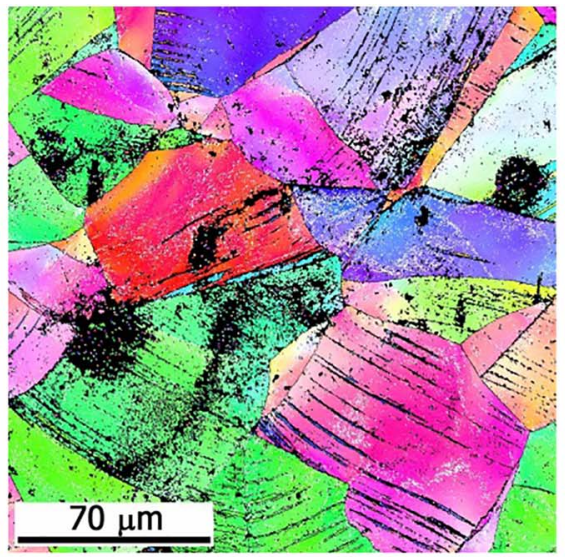

b

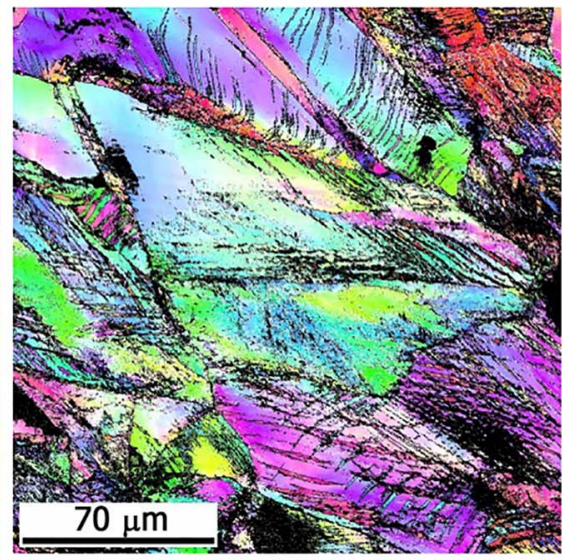

e

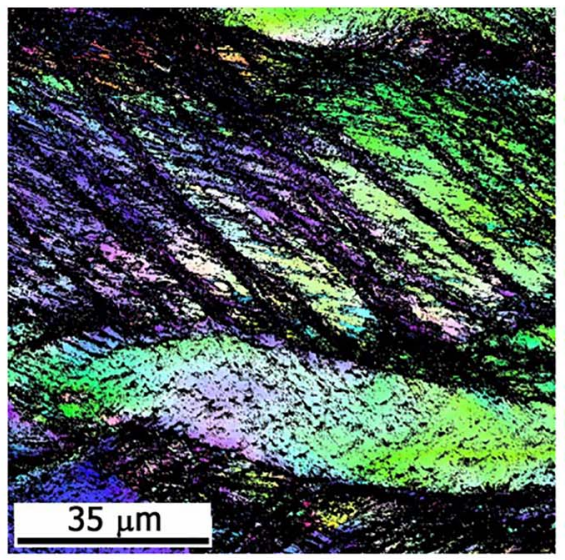

c

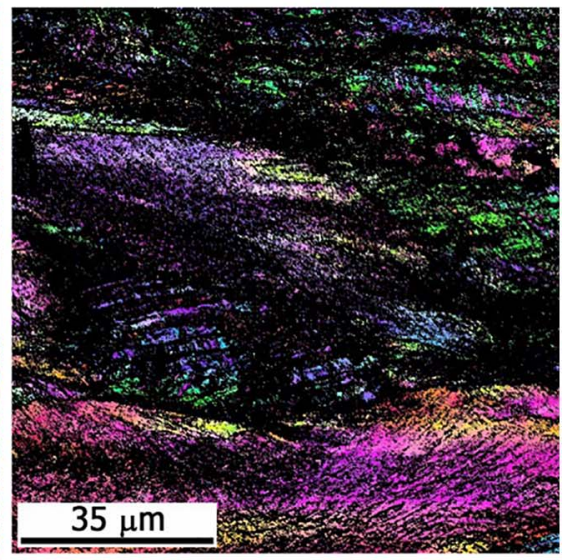

$\mathrm{f}$

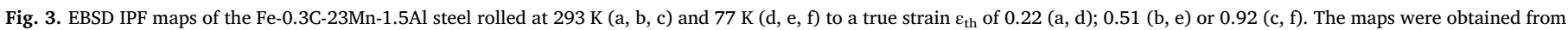

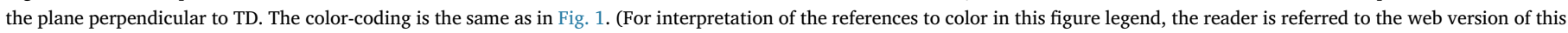
article.) 


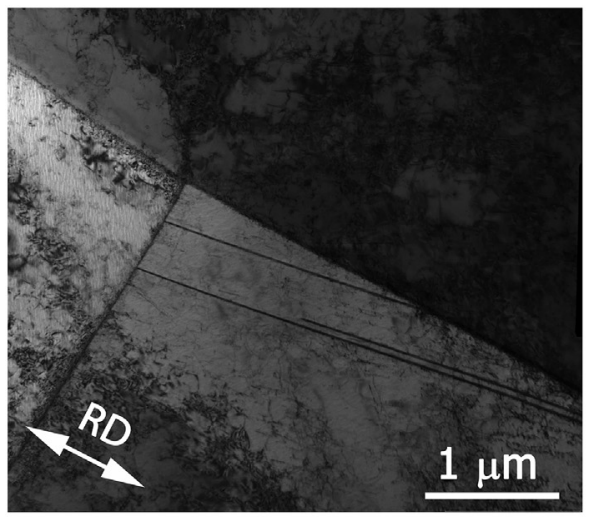

a

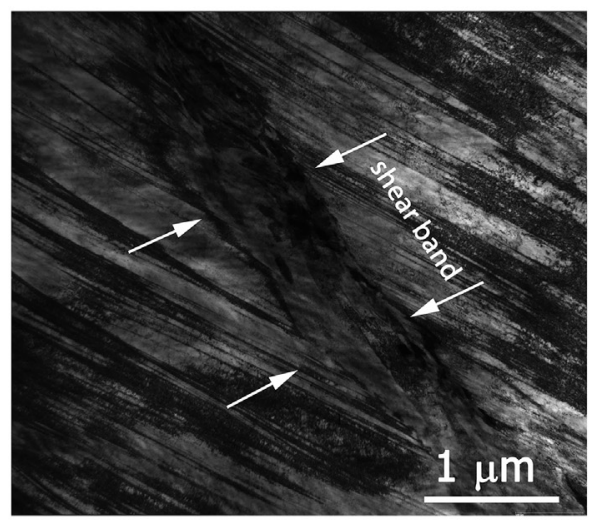

c

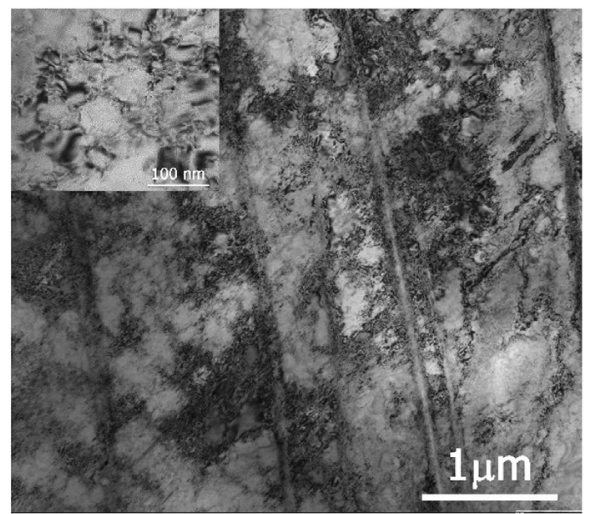

b

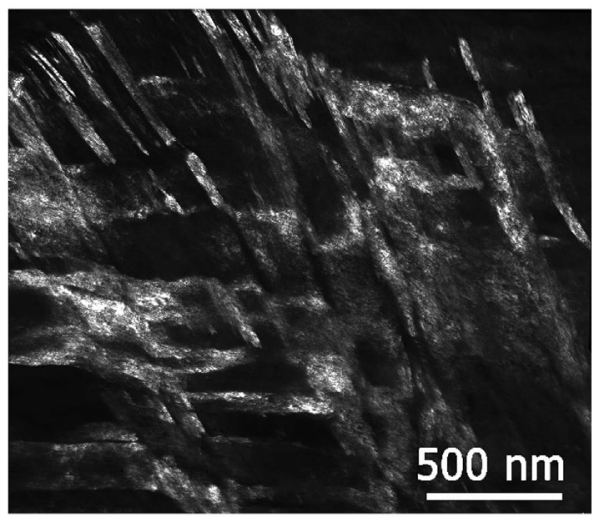

$\mathrm{d}$
Fig. 4. TEM bright-field (a-c) and dark-field (d) images of the Fe-0.3C-23Mn-1.5Al steel rolled at $293 \mathrm{~K}$ to a true strain $\varepsilon_{\text {th }}$ of 0.07 (a), 0.22 (b), and 0.92 (c, d). The images were obtained from the plane perpendicular to TD. quite similar to that observed after RT deformation to $\varepsilon_{\text {th }}=0.92$ (Fig. 4c, d). Increasing thickness reduction to $\varepsilon_{\text {th }}=0.92$ resulted in intensive formation of shear bands (Fig. $5 \mathrm{e}, \mathrm{f}$ ) in which considerable microstructure refinement was observed (Fig. 5f).

In the largely stained $\left(\varepsilon_{\mathrm{th}}=2.66\right)$ microstructure of the Fe-0.3C$23 \mathrm{Mn}-1.5 \mathrm{Al}$ steel no twin boundaries were observed in the rolling plane (Fig. 6). Most likely this is the effect of a highly anisotropic microstructure produced by large strain rolling due to a rotation of twin planes towards the rolling plane. Therefore, probably, twins were not observed in the rolling plane. Fragmentation of twins and decoration of twin boundaries by high density dislocation arrays also contributed to the absence of twins in TEM images. The microstructure of the steel after $\varepsilon_{\text {th }}=2.66$ at both temperatures can be described as a cellular one with a very high dislocation density (Fig. 6). However, close examination of the microstructure of the cryo-rolled steel revealed both irregular dislocation pile-ups of different shapes and sizes and very small grains with the size of $\sim 30-60 \mathrm{~nm}$ possessing high-angle boundaries (Fig. 6b). Such fine grains with high-angle boundaries were not found after rolling at room temperature.

Another important difference between the microstructures that form during rolling at $297 \mathrm{~K}$ and $77 \mathrm{~K}$ is formation of the strain-induced $\varepsilon$ martensite in the latter case. X-ray diffraction analysis revealed that a noticeable amount of the $\varepsilon$-martensite $(\sim 14 \%)$ appear in the steel already after smallest deformation $\left(\varepsilon_{\text {th }}=0.07\right)$ at $77 \mathrm{~K}$. This amount of the strain-induced martensite increases with strain attaining $\sim 30 \%$ at $\varepsilon_{\text {th }}>0.36$ and does not change markedly with further increase of rolling strain. At room temperature no measurable amount of the $\varepsilon$ martensite was found to form at any strains. TEM inspection (Fig. 7) has also revealed presence of the $\varepsilon$-martensite; it has a plate-like morphology and the plates of the $\varepsilon$-martensite appear very much alike deformation twins.

Quantitative analysis (Fig. 8) of microstructure evolution of the investigated steel showed quite similar behavior of the material at both temperatures. The spacing between twin boundaries (Fig. 8a) decreased with strain attaining the value of $0.05-00.7 \mu \mathrm{m}$ at $\varepsilon_{\text {th }}=0.92$. At cryogenic temperature, more intensive twinning at the earlier stages of strain up to $\varepsilon_{\text {th }}=0.36$ resulted in smaller inter-twin distances. At higher strains, the spacing between twin boundaries became very similar after rolling at both temperatures. Dislocation density (Fig. 8b) increased relatively fast at the initial stages of strain. However, after $\varepsilon_{\mathrm{th}}=0.22$ the increase in the dislocation density became much slower. At room temperature, the dislocation density was found to be noticeably higher during initial stages of deformation (up to $\varepsilon_{\text {th }}=0.22$ ) than that after deformation cryogenic temperature. After further rolling (to strains of 0.51 and 0.92 ) at both temperatures, the dislocation density was estimated to be very similar. At highest examined strain of $\varepsilon_{\text {th }}=2.66$ much higher dislocation density was found at room temperature (Fig. 8b).

\subsection{Texture Evolution}

The texture evolution of the investigated TWIP steel during rolling at $293 \mathrm{~K}$ and $77 \mathrm{~K}$ is illustrated in Fig. 9. The main texture components typical for face-centered cubic (fcc) metals are shown in Fig. 9c and defined in Table 1. At both rolling temperatures, the texture evolution was mainly associated with the development of the $\alpha$-fiber ( $\langle 110\rangle \| \mathrm{ND}$ ); at the very late stages of deformation $\gamma$-fiber texture components ( $\langle 111\rangle \| N D)$ were also observed. At the initial rolling stages, the textures of the samples deformed at both temperatures were found to be rather similar and were characterized by the $\alpha$-fiber without prominent maximums.

Only at $\varepsilon_{\text {th }} \geq 0.51$ maximums corresponding to Brass $(\{110\}$ $\langle 112\rangle)$ and Gross ( $\{110\}\langle 100\rangle)$ texture components developed at both temperatures. However, it should be noted that these texture 


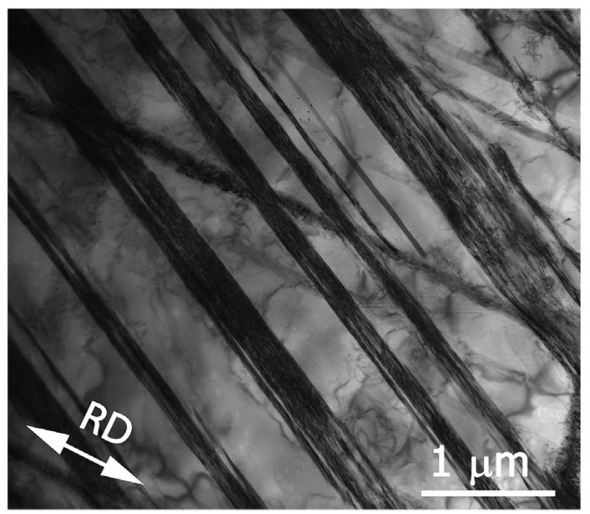

a

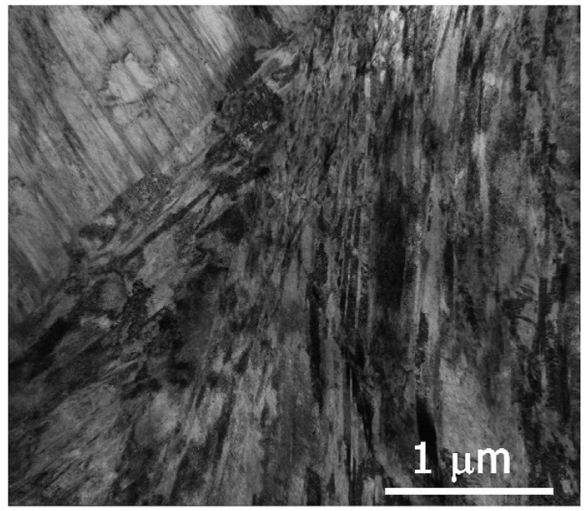

$\mathrm{c}$

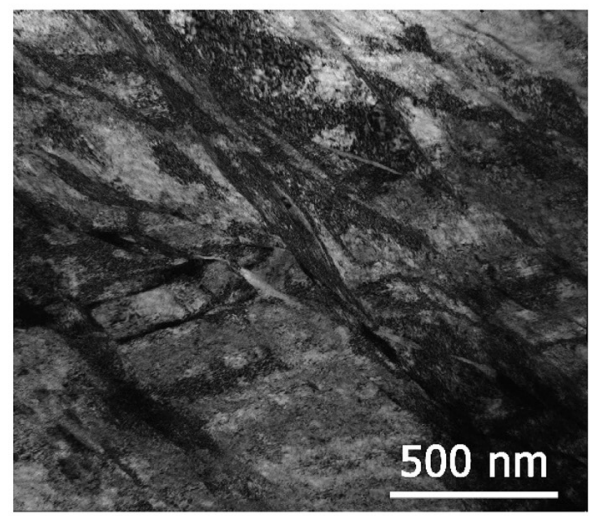

e

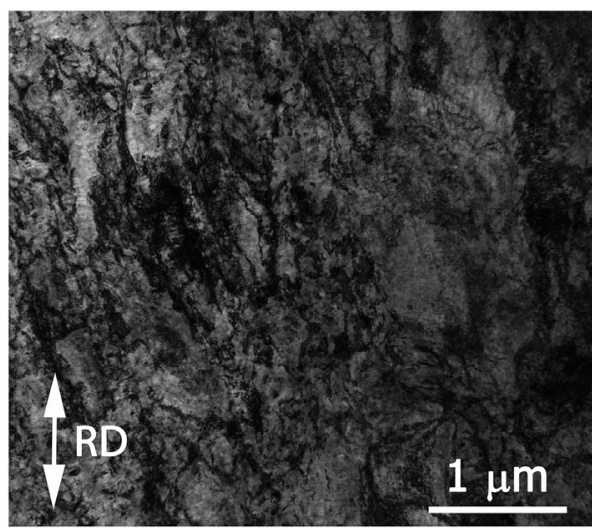

a

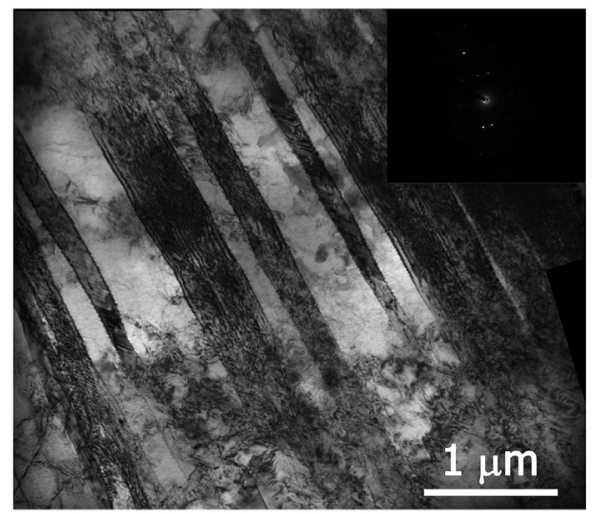

b

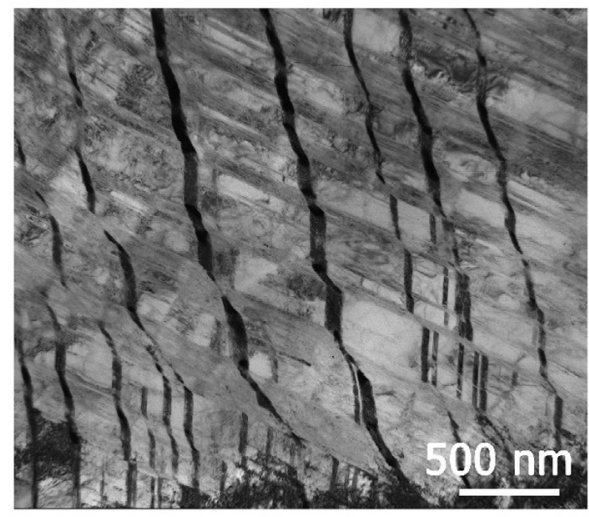

d

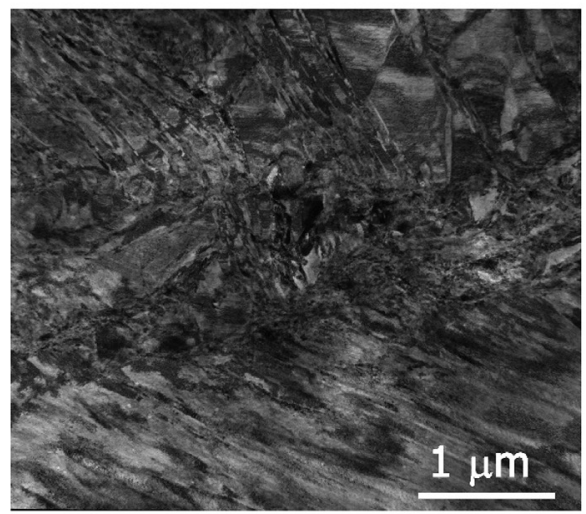

f

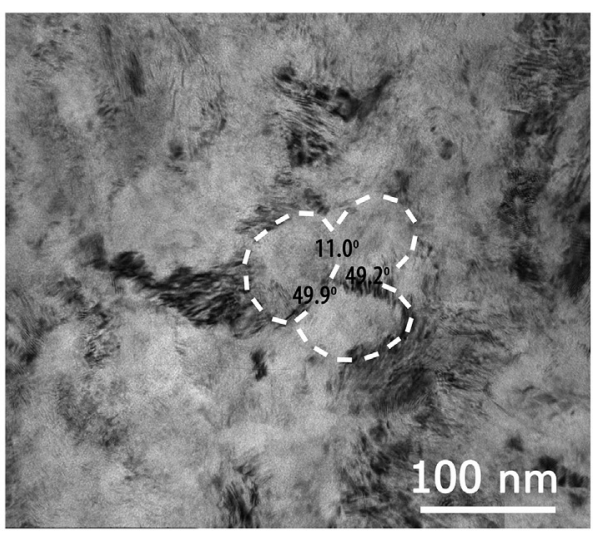

b
Fig. 5. TEM bright-field images of the Fe-0.3C-23Mn-1.5A steel rolled at $77 \mathrm{~K}$ to a true strain $\varepsilon_{\text {th }}$ of 0.07 (a), 0.22 (b), $0.51(\mathrm{c}, \mathrm{d})$ or 0.92 (e, f). The images were obtained from the plane perpendicular to TD.
Fig. 6. TEM bright-field images of the specimens rolled to a true strain $\varepsilon_{\text {th }}$ of 2.66 at $293 \mathrm{~K}$ (a) and $77 \mathrm{~K}$ (b). The images were obtained from the rolling plane. 


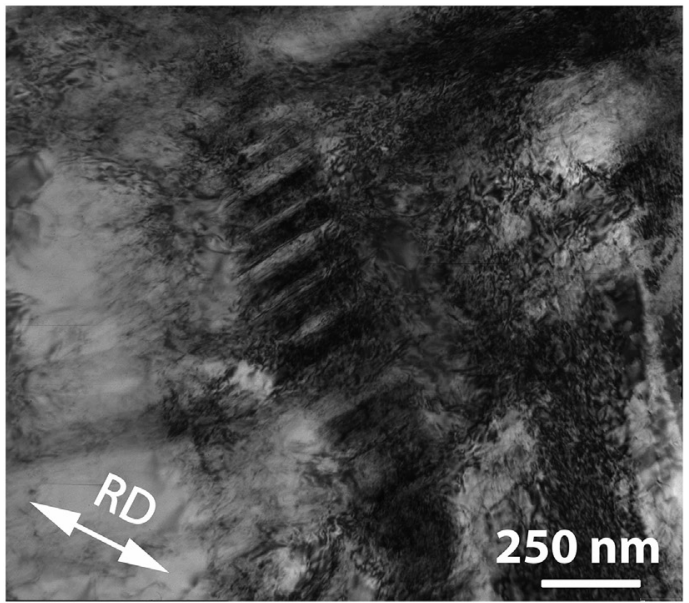

a

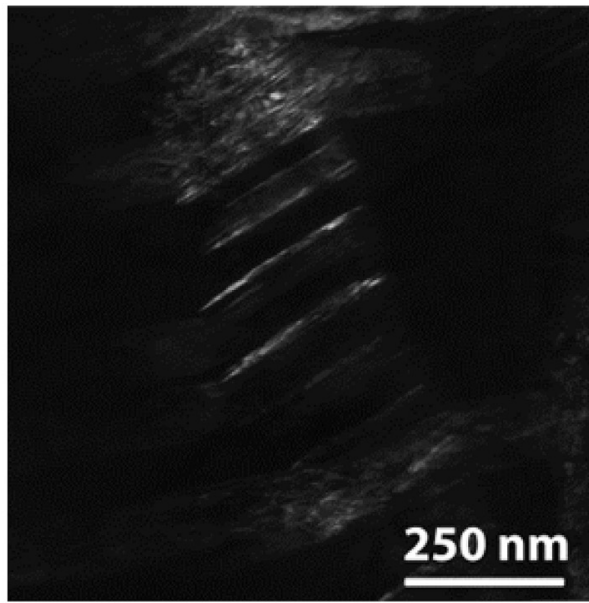

b

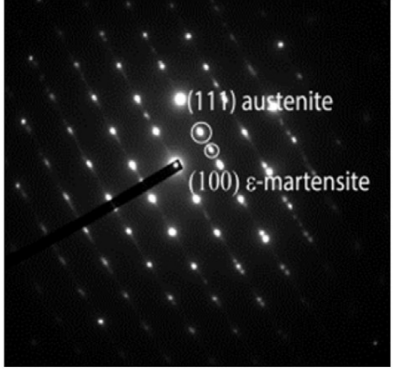

c

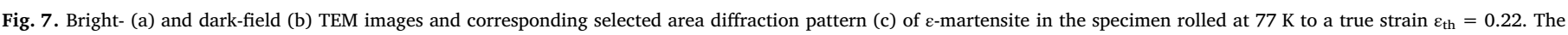
images were obtained from the plane perpendicular to TD.

components developed more intensively and at lower strains at $77 \mathrm{~K}$. At highest rolling strains, i.e. from 0.92 to 2.66 , the $\alpha$-fiber texture components developed further during rolling at $293 \mathrm{~K}$, whereas a weakening was observed for rolling at $77 \mathrm{~K}$ (Fig. 9a, b). The development of the rolling texture, which occurred at lower strains during rolling at $77 \mathrm{~K}$ was also indicated by the evolution of the texture index (TI), as shown in Fig. 10a. Furthermore, the TI also verified the weakening between true strains of 0.92 and 2.66 .

The evolution of the volume fractions of the main texture components during rolling is shown in Fig. 10b and c. During rolling at $293 \mathrm{~K}$ (Fig. 10b) continuous development of the rather strong Brass and Goss and rather weak CuT ( $\{552\}\langle 115\rangle)$ texture components with increasing strain was observed. The intensities of the rather strong $S$ $(\{123\}\langle 634\rangle)$ and weak $\mathrm{Cu}$ texture components were weakly affected by rolling strain. Finally, the intensity of the $\mathrm{E}+\mathrm{F}$ texture component was weak at strain below 0.92 , but it increased pronouncedly at higher strains. Qualitatively, the texture evolution during cryogenic rolling (Fig. 10c) was similar to the room temperature case. It is, however, worth noting that the CuT texture component developed more pronounced at $77 \mathrm{~K}$ as compared to $293 \mathrm{~K}$, especially at higher rolling degrees starting from 0.36 . The intensity of most components (except for the $\mathrm{E}+\mathrm{F}$ component) decreased with increasing strain to 0.92 and

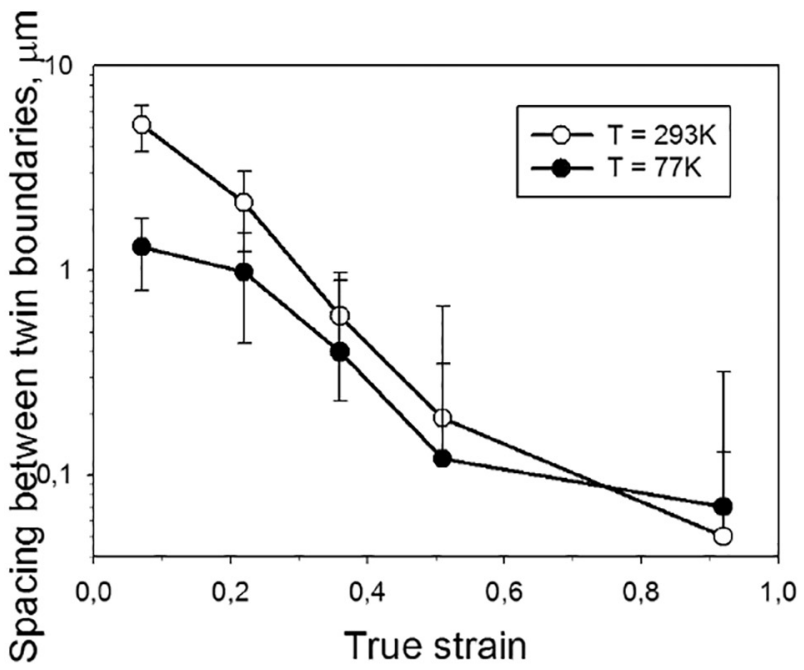

a
2.66 in cryogenic condition unlike the RT rolling.

\subsection{Mechanical Properties}

True stress-true strain curves derived from load-stroke data prior to necking for tension testing of samples previously rolled at $293 \mathrm{~K}$ and $77 \mathrm{~K}$ to various thickness strains are shown in Fig. 11a and b, respectively. As noted in Section 2, all tension tests were conducted at room temperature.

Samples rolled at $293 \mathrm{~K}$ (Fig. 11a), to $\varepsilon_{\text {th }}=0.22$ exhibited a steady increase in the true stress with strain and a relatively high uniform elongation of $\sim 0.3-0.55$. An increase in strain during rolling to 0.92-2.66 resulted in the elimination of the strain hardening stage and early necking that is typical for severely cold-worked materials. Specimens rolled to 0.36 and 0.51 strain showed a transient behavior with a rather short strain hardening stage.

The tension test results for cryo-rolled samples (Fig. 11b) were qualitatively similar to those for samples rolled at room temperature. Principal differences comprised higher flow stress and smaller uniform deformation in the specimens rolled at $77 \mathrm{~K}$ to $\varepsilon_{\text {th }} \geq 0.22$.

From an application standpoint, although the maximum ultimate tensile strength of the examined TWIP steel after room temperature or

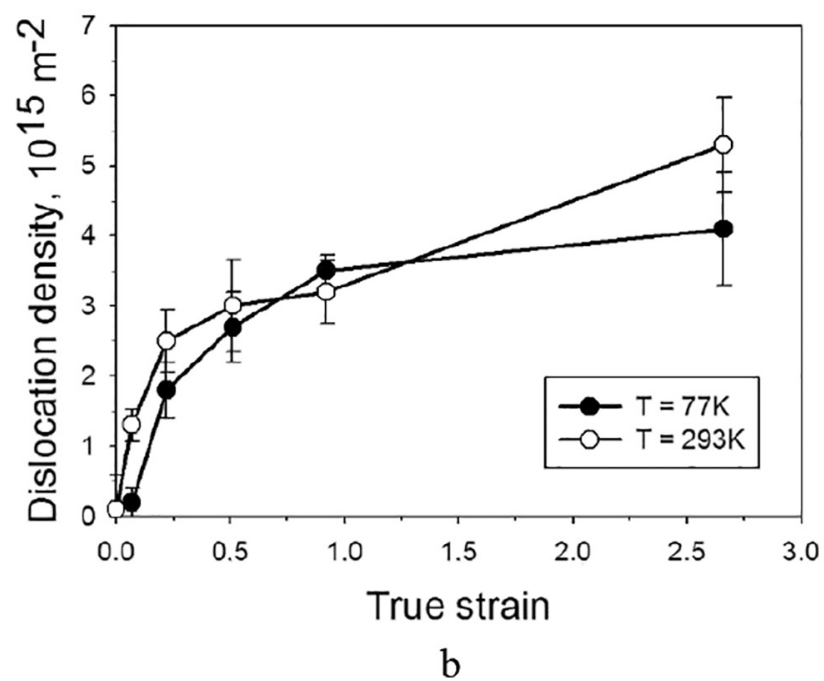

Fig. 8. Spacing between twin boundaries (a) and dislocation density (b) as a function of a true strain $\varepsilon_{\text {th }}$. 

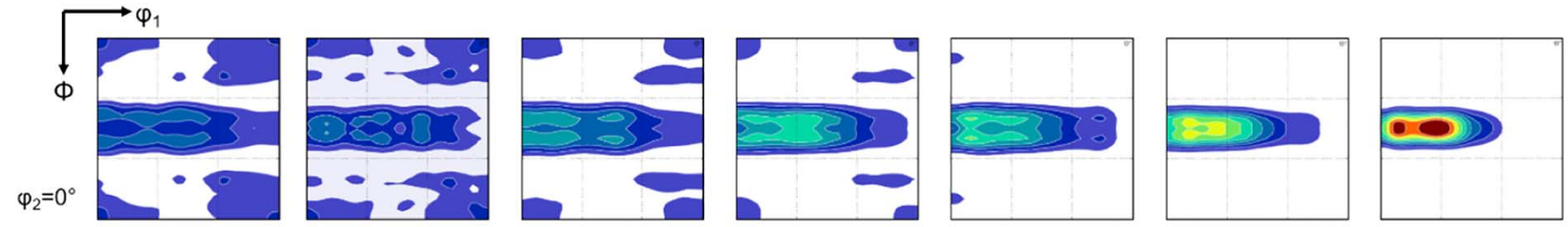

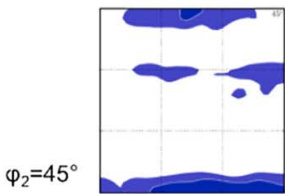

0.07

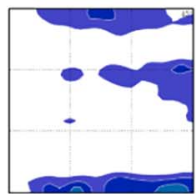

0.1

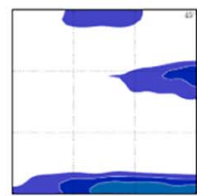

0.22
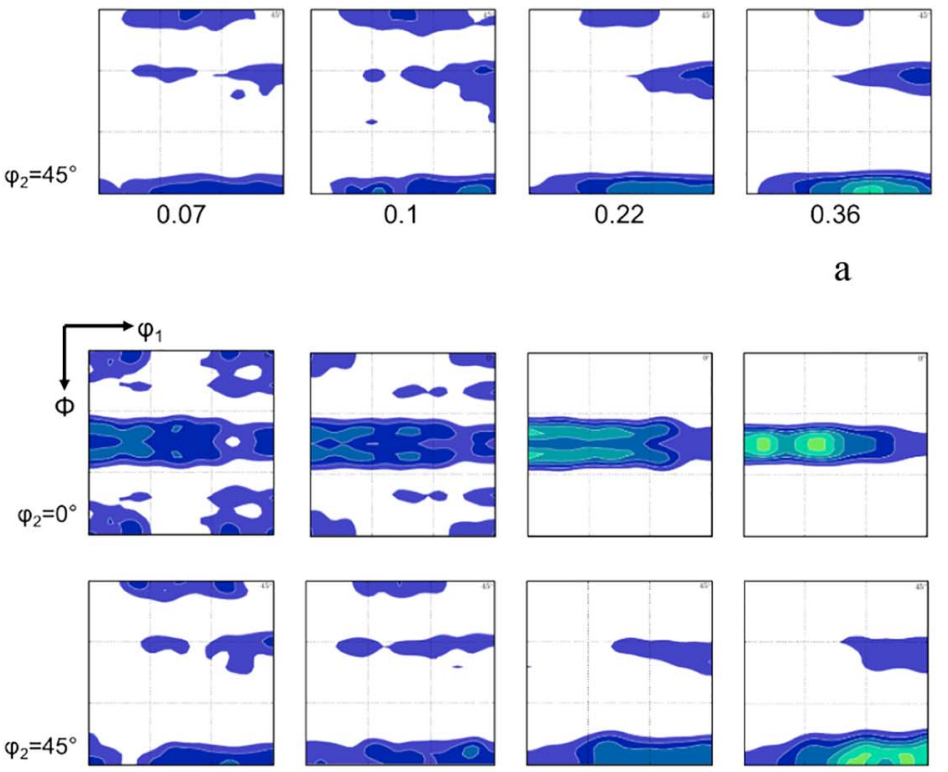

0.07
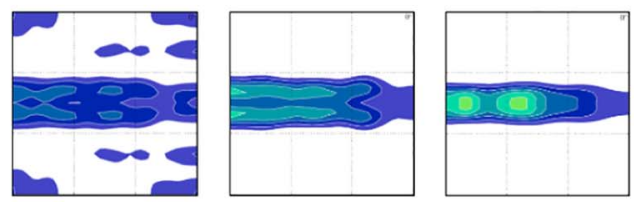
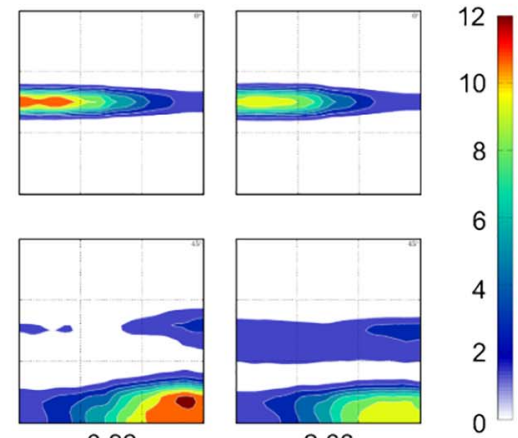

0.36

a
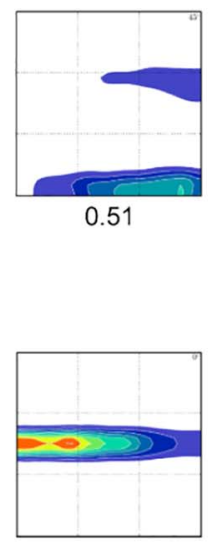

0.51

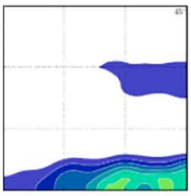

0.36

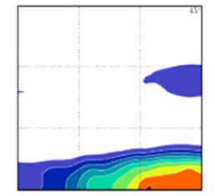

0.51

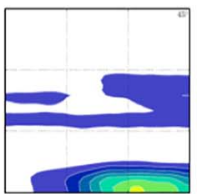

0.92

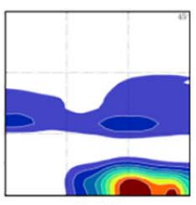

2.66
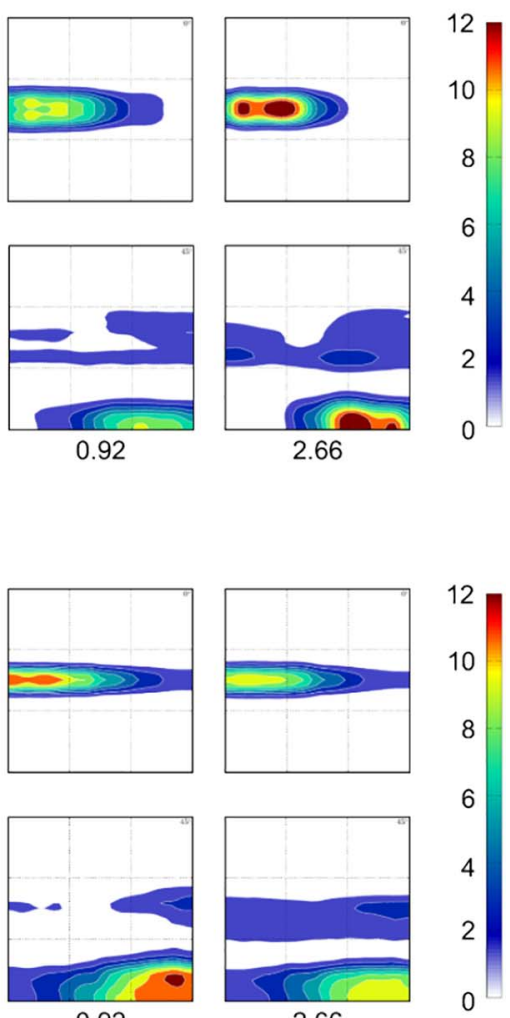

0

$\mathrm{b}$
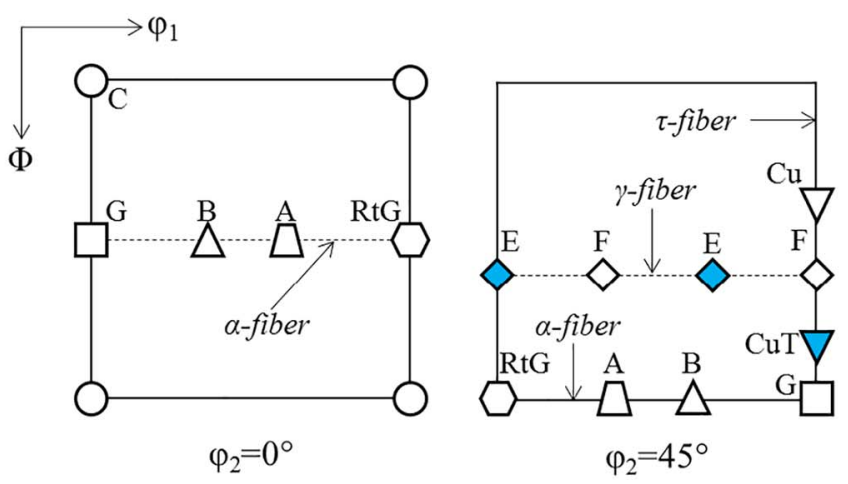

C

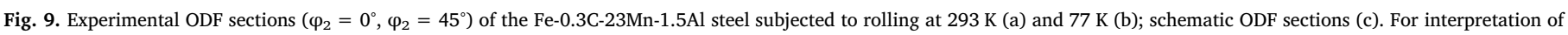
ideal orientation shown in panel c refer to Table 1 .

Table 1

Definition of texture components.

\begin{tabular}{lllll}
\hline Component & Symbol & Miller indices & Euler angles $\left(\varphi_{1}, \Phi, \varphi_{2}\right.$ & Fiber \\
\hline Brass (B) & $\Delta$ & $\{110\}\langle 112\rangle$ & $(55,90,45)$ & $\alpha, \beta$ \\
Goss (G) & $\square$ & $\{110\}\langle 100\rangle$ & $(90,90,45)$ & $\alpha, \tau$ \\
Rotated Goss (RtG) & $\square$ & $\{110\}\langle 110\rangle$ & $(0,90,45)$ & $\alpha$, \\
A & $\square$ & $\{110\}\langle 111\rangle$ & $(35,90,45)$ & $\alpha$, \\
Cube (C) & $\bigcirc$ & $\{001\}\langle 100\rangle$ & $(45,0,45)$ & $/$ \\
E & $\bullet$ & $\{111\}\langle 110\rangle$ & $(0 / 60,55,45)$ & $\gamma$ \\
F & $\diamond$ & $\{111\}\langle 112\rangle$ & $(30 / 90,55,45)$ & $\gamma$ \\
Copper (Cu) & $\nabla$ & $\{112\}\langle 111\rangle$ & $(90,35,45)$ & $\beta, \tau$ \\
Copper Twin (CuT) & $\nabla$ & $\{552\}\langle 115\rangle$ & $(90,74,45)$ & $\tau$ \\
S & $\oplus$ & $\{123\}\langle 634\rangle$ & $(59,37,63)$ & $\beta$ \\
$\alpha$-Fiber & $\langle 110\rangle$ & parallel to ND & & \\
$\gamma$-Fiber & $\langle 111\rangle$ & parallel to ND & & \\
$\tau$-Fiber & $\langle 110\rangle$ & parallel to TD & & \\
\hline
\end{tabular}

cryo-rolling to $\varepsilon_{\text {th }}=2.66$ was $1820 \mathrm{MPa}$ and $1990 \mathrm{MPa}$, respectively, rolling to $\varepsilon_{\text {th }}=0.22$ at both temperatures, however, seems to be more attractive because of a reasonable balance between strength and ductility (Table 2). At RT rolling to $\varepsilon_{\mathrm{th}}=0.22$ the ultimate tensile strength and the uniform elongation were $1235 \mathrm{MPa}$ and 0.310 , and after rolling at cryogenic temperature $1138 \mathrm{MPa}$ and 0.123 , respectively.

Additional information on the mechanical behavior of steel specimens during deformation at $293 \mathrm{~K}$ and $77 \mathrm{~K}$ was obtained using microhardness tests (Fig. 12). Both curves increased monotonically with strain; however the microhardness of the cryo-rolled specimens is noticeably higher than that of the RT-rolled specimens for the entire deformation range.

\section{Discussion}

The results of the present work revealed a pronounced influence of 


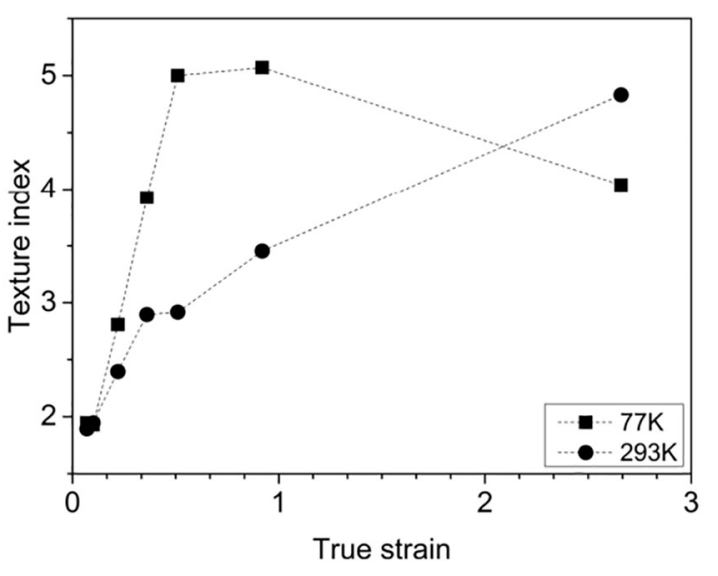

a

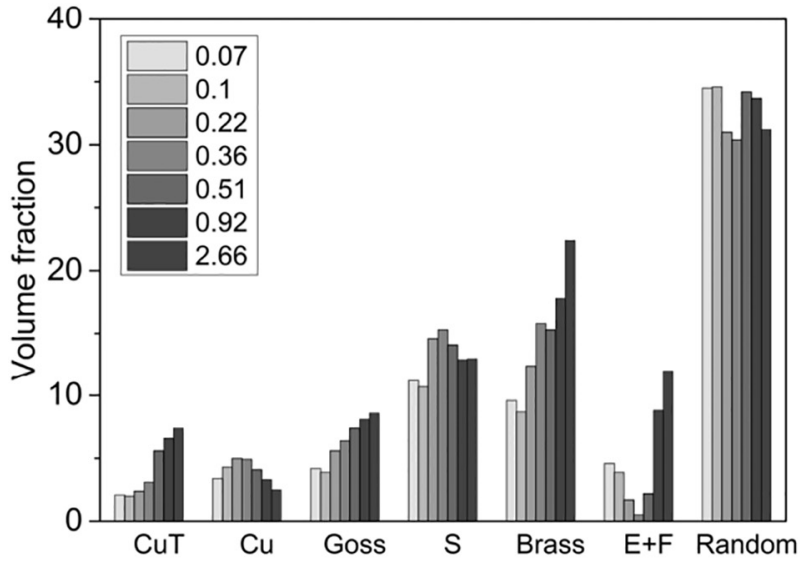

$\mathrm{b}$

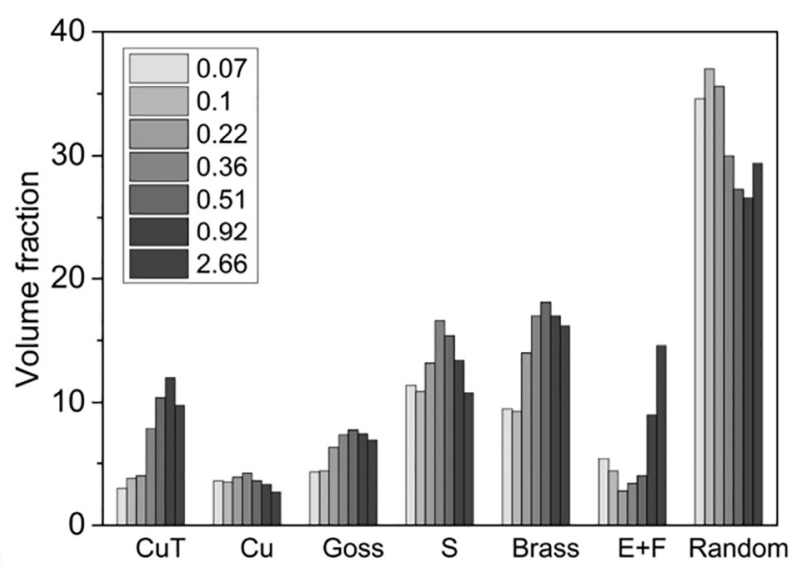

C

Fig. 10. Evolution of the texture index (a) and of the volume fractions of the main texture components of the Fe-0.3C-23Mn-1.5Al steel during rolling at $293 \mathrm{~K}$ (b) and $77 \mathrm{~K}$ (c).

cryo-rolling on the structure and properties of the Fe-0.3C-23Mn-1.5Al TWIP steel. The main features of the microstructure evolution during deformation at $77 \mathrm{~K}$ comprised intensive twinning followed by more pronounced shear deformation and formation of a considerable amount of $\varepsilon$-martensite in comparison with those observed at $293 \mathrm{~K}$.

Deformation twinning is intrinsic to TWIP steels due to low values of the SFE which can be evaluated in this specific steel to be $\sim 25 \mathrm{~mJ} /$

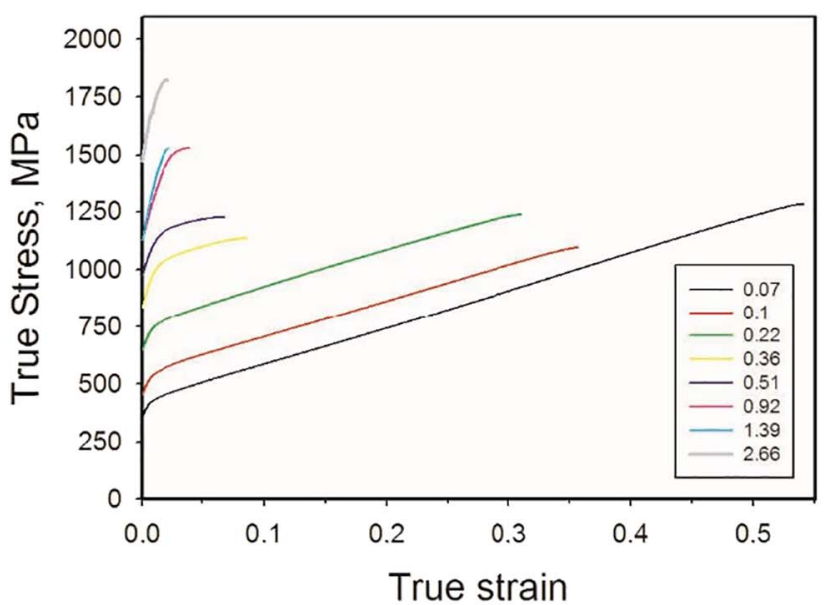

a $\mathrm{m}^{2}$ [27]. However, at the initial stages of plastic flow, the formation of twins is noticeably more active at $77 \mathrm{~K}$, while at RT the steel predominantly deform by dislocation movement (Figs. 4, 5, 8b). This temperature-induced competition between slip and twinning in fcc alloys is likely associated (at the given chemical composition and the strain rate) with a decrease in values of SFE at lower temperatures $[28,29]$ and with a corresponding change in the ratio between resolved

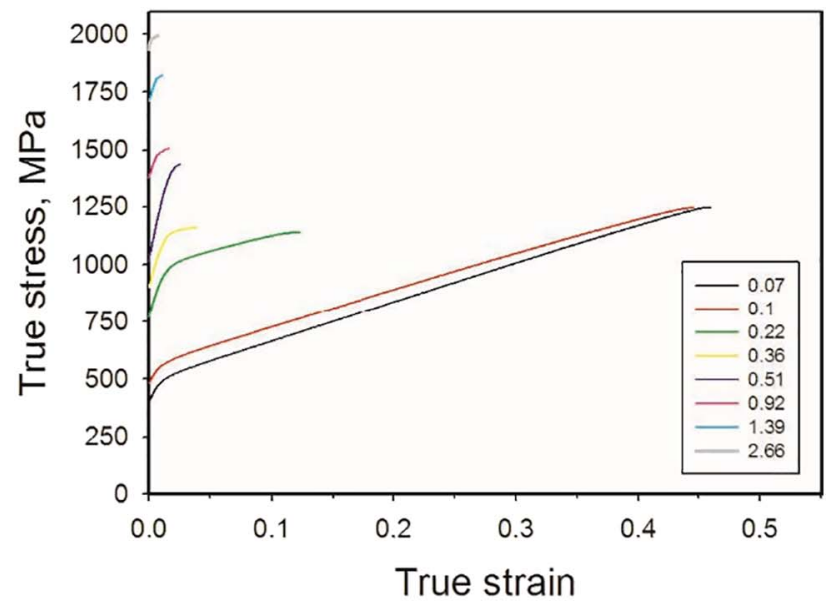

b

Fig. 11. True stress-true strain curves for steel rolled at $293 \mathrm{~K}$ (a) and $77 \mathrm{~K}$ (b) to strains in the range between 0.07 and 2.66 . 
Table 2

Mechanical properties of the Fe-0.3C-23Mn-1.5Al steel.

\begin{tabular}{llllll}
\hline$\varepsilon_{\text {th }}$ & & $\begin{array}{l}\text { Ultimate tensile } \\
\text { strength, MPa }\end{array}$ & $\begin{array}{l}\text { Yield } \\
\text { strength, MPa }\end{array}$ & $\begin{array}{l}\text { Uniform } \\
\text { elongation }\end{array}$ & $\begin{array}{l}\text { Total } \\
\text { elongation }\end{array}$ \\
\hline 0.07 & $293 \mathrm{~K}$ & 1283 & 383 & 0.541 & 0.565 \\
& $77 \mathrm{~K}$ & 1246 & 424 & 0.459 & 0.472 \\
0.1 & $293 \mathrm{~K}$ & 1093 & 481 & 0.357 & 0.374 \\
& $77 \mathrm{~K}$ & 1244 & 502 & 0.445 & 0.471 \\
0.22 & $293 \mathrm{~K}$ & 1235 & 677 & 0.310 & 0.337 \\
& $77 \mathrm{~K}$ & 1138 & 809 & 0.123 & 0.136 \\
0.36 & $293 \mathrm{~K}$ & 1133 & 874 & 0.086 & 0.104 \\
& $77 \mathrm{~K}$ & 1158 & 942 & 0.038 & 0.050 \\
0.51 & $293 \mathrm{~K}$ & 1224 & 1010 & 0.068 & 0.103 \\
& $77 \mathrm{~K}$ & 1430 & 1070 & 0.025 & 0.046 \\
0.92 & $293 \mathrm{~K}$ & 1528 & 1169 & 0.039 & 0.073 \\
& $77 \mathrm{~K}$ & 1706 & 1420 & 0.016 & 0.033 \\
1.39 & $293 \mathrm{~K}$ & 1525 & 1180 & 0.022 & 0.032 \\
& $77 \mathrm{~K}$ & 1822 & 1744 & 0.011 & 0.020 \\
2.66 & $293 \mathrm{~K}$ & 1824 & 1541 & 0.021 & 0.025 \\
& $77 \mathrm{~K}$ & 1993 & 1978 & 0.007 & 0.011 \\
\hline
\end{tabular}

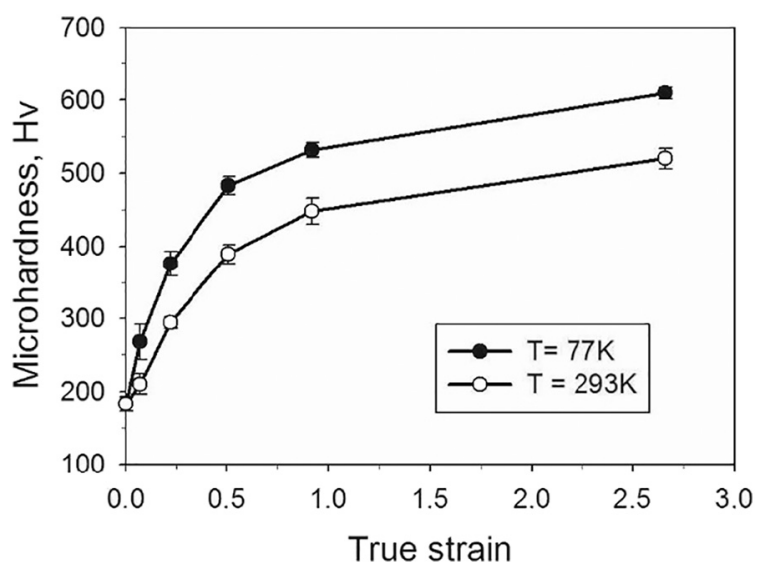

Fig. 12. Microhardness of the Fe-0.3C-23Mn-1.5Al TWIP steel as a function of strain during rolling at $293 \mathrm{~K}$ and $77 \mathrm{~K}$.

stress for twinning and dislocation glide [30]. However, it should be noted that a variation in temperature in the interval between $77 \mathrm{~K}$ and $293 \mathrm{~K}$ with respect to a high manganese fcc Fe-20Mn-0.6C alloy was reported to yield a rather weak change of SFE [27]. The results of the present work therefore suggest that either the decrease in SFE was greater than it was expected in [27] or the slip-to-twining transition in
TWIP steels is quite sensitive to deformation temperature.

Another finding that indicates a pronounced effect of the decrease in temperature from $293 \mathrm{~K}$ to $77 \mathrm{~K}$ is the intensive formation of $\varepsilon$-martensite (up to $30 \%$ ) at the lower temperature. It is obvious that the value of stress needed for martensite formation decreases while temperature of deformation becomes close to the Ms. point (temperature of the onset of martensitic transformation). Thus, the plastic strain required to produce the same amount of $\varepsilon$-martensite decreases with decreasing deformation temperature [31]. In addition the ease of the $\mathrm{fcc} \rightarrow$ hcp transformation in the TWIP steel at $77 \mathrm{~K}$ can also be associated with lower critical stress for $\varepsilon$-martensite nuclei formation due to decreased values of SFE [32].

The microstructural changes in the TWIP steel during rolling at room and cryogenic temperature was found to be closely related with texture evolution. As it was reported in a number of previous studies $[18,19,33-36]$, room temperature rolling of fcc TWIP steels is associated with the formation of Copper-type texture in the beginning of deformation and transition to Brass-type texture during further rolling. Generally the development of texture components during rolling of TWIP steels can be divided into three stages: (i) increase of $\mathrm{S}, \mathrm{Cu}$ and Goss components due to more active dislocation slip at early stages of deformation (till $\varepsilon_{\text {th }} \approx 0.22$ ) (ii) increase in Goss and CuT components after the onset of intensive twinning $\left(\varepsilon_{\text {th }} \approx 0.36-0.51\right)$ and (iii) development of a weak $\gamma$-fiber with increased $\mathrm{F}$ and $\mathrm{E}$ components caused by activation of shear deformation $\left(\varepsilon_{\text {th }} \approx 0.92-2.66\right)$.

The decreased temperature of rolling $(77 \mathrm{~K})$ changed the contribution of various texture components during the texture evolution. A lower volume fraction of the $\mathrm{Cu}$ component and a higher volume fraction of the CuT component at $77 \mathrm{~K}$ can be associated with more intensive twinning and less active slip (Figs. 5, 7, 8). As a consequence, the transition from Copper-type to Brass-type texture occurred at lower rolling strains at $77 \mathrm{~K}$. Meanwhile the formation of $\varepsilon$-martensite at $77 \mathrm{~K}$ decreases the contribution of twinning to the deformation process and thus reduced the volume fractions of the twinning-related components (Goss and CuT [19]). Besides, decrease in the volume fraction of all texture components at $\varepsilon_{\text {th }} \geq 0.92$, except for $\mathrm{E}+\mathrm{F}$ components, can indicate predominance of shear deformation [34] during rolling at $77 \mathrm{~K}$ in contrast to that at room temperature.

More intensive twinning at $77 \mathrm{~K}$ resulted in smaller space between twin boundaries that, in turn, should result in more pronounced strengthening effect. The formation of small grains with the size of $30-50 \mathrm{~nm}$ and high dislocation density are other factors that can provide very high strength. The contributions of different hardening mechanisms in strength of the steel during deformation at both

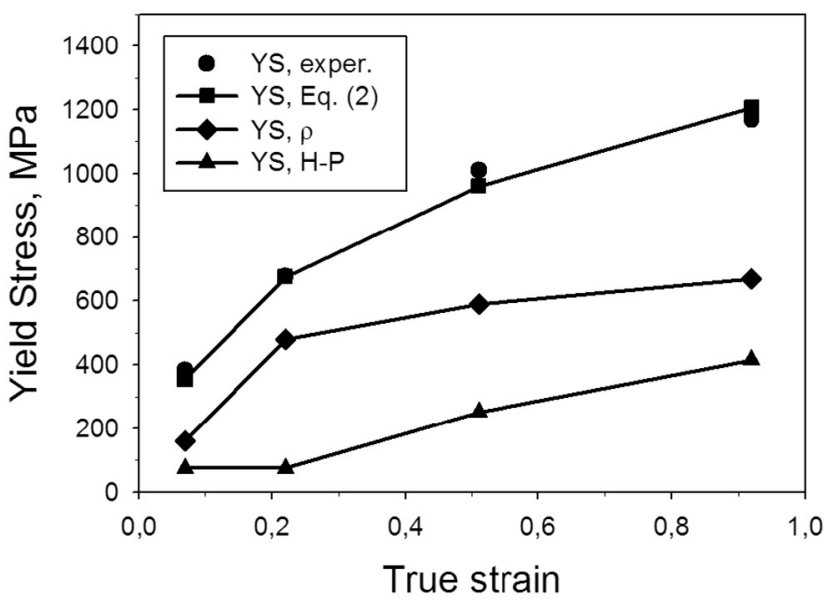

a

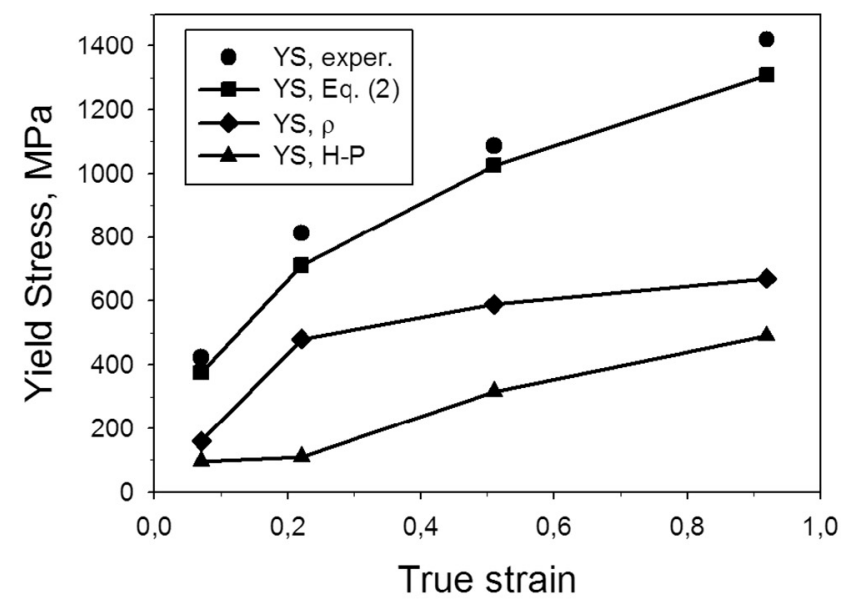

b

Fig. 13. Contribution of different strengthening mechanisms to the overall strength of steel rolled at $293 \mathrm{~K}$ (a) and $77 \mathrm{~K}$ (b) to various strains. 
temperatures are shown in Fig. 13. The overall strength can be typically expressed as:

$\sigma=\sigma_{0}+\sigma_{\rho}+\sigma_{\mathrm{H}-\mathrm{P}}$

where $\sigma_{0}$ denotes the friction stress, $\sigma_{\rho}$ is the substructure hardening and $\sigma_{\mathrm{H}-\mathrm{P}}$ is the Hall-Petch hardening. The substructure hardening $\sigma_{\rho}$ can be expressed as:

$\sigma_{\rho}=\operatorname{MaGb} \sqrt{\rho}$

where $M=3$ is the average Taylor factor, $\alpha$ is a constant, $G$ is the shear modulus, $\mathrm{b}$ is the Burgers vector and $\rho$ is the dislocation density. The Hall-Petch contribution to the strength is typically of the form:

$\sigma_{\mathrm{H}-\mathrm{P}}=\mathrm{K}_{\mathrm{y}} \mathrm{d}^{-1 / 2}$

in which $\mathrm{K}_{\mathrm{y}}$ is the Hall-Petch coefficient and $\mathrm{d}$ is the grain size. In the present work the following parameters were used: $\alpha=0.21$ and $\mathrm{K}_{\mathrm{y}}=0.11 \mathrm{MPa} \mathrm{m}^{0.5}, \mathrm{M}=3, \mathrm{G}=72 \mathrm{GPa}, \mathrm{b}=2.5 \times 10^{-10} \mathrm{~m}$ [37]. The value of $\sigma_{0}=120 \mathrm{MPa}$ was experimentally determined as the yield stress of the steel in the coarse-grained (initial) condition. The values of grain sizes were taken from Fig. 8a as the spacing between twin boundaries.

At both temperatures the main contribution in strength was provided by the substructure strengthening which is approximately two times higher than the Hall-Petch effect. It can be therefore concluded that the contribution of grain refinement in the investigated material is less important for the overall strengthening compared to the increased dislocation density. Similar results were obtained for different TWIP steels rolled to $80-90 \%$ at room temperature $[17,36,37]$.

\section{Conclusions}

Mechanical behavior and evolution of microstructure and texture during rolling of a Fe-0.3C-23Mn-1.5Al TWIP steel at $77 \mathrm{~K}$ and $293 \mathrm{~K}$ was investigated. The following conclusions can be drawn from this work:

1. Microstructure evolution in the steel during rolling at both temperatures ( $77 \mathrm{~K}$ and $293 \mathrm{~K}$ ) was associated with twinning, followed by shear banding. At $77 \mathrm{~K}$, twinning was more pronounced, occurred at lower rolling strains, and also $\varepsilon$-martensite formation was activated due to the lower SFE as compared to rolling at $293 \mathrm{~K}$.

2. Three stages of texture evolution can be recognized during rolling of the investigated TWIP steel: (i) increase of $\mathrm{S}, \mathrm{Cu}$, and Goss texture components due to more active dislocation slip at early stages of deformation (till $\varepsilon_{\mathrm{th}} \approx 0.22$ ); (ii) increase in Goss and CuT texture components after the onset of intensive twinning $\left(\varepsilon_{\text {th }} \approx 0.36-0.92\right)$; and (iii) development of a weak $\gamma$-fiber with increased $\mathrm{F}$ and $\mathrm{E}$ texture components caused by activation of shear deformation ( $\varepsilon_{\mathrm{th}} \approx 0.92-2.66$ ). The transition from Copper-type to Brass-type texture was shifted to lower strains during rolling at $77 \mathrm{~K}$ due to the decreased SFE and more pronounced twinning. The formation of $\varepsilon$ martensite at $77 \mathrm{~K}$ was a possible reason for the reducing the volume fractions of twinning-related texture components.

3. Rolling at $77 \mathrm{~K}$ to a true thickness strain of 2.66 resulted in the formation of a microstructure with a grain size of 30-60 $\mathrm{nm}$ while a cellular microstructure with high dislocation density was observed after rolling at $293 \mathrm{~K}$. The ultimate tensile strength of the investigated steel was 1990 and $1850 \mathrm{MPa}$ after rolling to a true thickness strain of 2.66 at $77 \mathrm{~K}$ and $293 \mathrm{~K}$, respectively. Calculation of the contribution of different strengthening mechanisms to the yield strength revealed that strengthening due to work hardening, i.e. the influence of the dislocation density, is the dominant mechanisms in TWIP steels.

\section{Acknowledgement}

The reported study was funded by RFBR according to the research project No. 16-38-00550 мол_а. The authors are also grateful to the personnel of the Joint Research Center, "Technology and Materials", Belgorod State National Research University, for their assistance with the experimental analysis. C.H. and D.A.M. acknowledge gratefully the financial support of the Deutsche Forschungsgemeinschaft (DFG) within the Collaborative Research Center (SFB) 761 'Steel - ab initio; quantum mechanics guided design of new Fe based materials'.

\section{References}

[1] O. Bouaziz, S. Allain, C.P. Scott, P. Cugy, D. Barbier, High manganese austenitic twinning induced plasticity steels: a review of the microstructure properties relationships, Curr. Opin. Solid State Mater. Sci. 15 (4) (2011) 141-168.

[2] S. Allain, J.-P. Chateau, O. Bouaziz, Constitutive model of the TWIP effect in a polycrystalline high manganese content austenitic steel, Steel Res. 73 (2002) 299-302.

[3] B.C. De Cooman, K.G. Chin, J. Kim, High Mn TWIP steels for automotive applications, in: M. Chiaberge (Ed.), New Trends and Developments in Automotive System Engineering, InTech publ., 2011, pp. 103-105.

[4] J.-P. Chateau, A. Dumay, S. Allain, A. Jacques, Precipitation hardening of a FeMnC TWIP steel by vanadium carbides, J. Phys. Conf. Ser. 240 (2010) 012023.

[5] D. Zamani, A. Najafizadeh, H. Monajati, G. Razavi, The effect of thermo-mechanical treatment and adding niobium and titanium on microstructure and mechanical properties of TWIP steel, Int. J. Appl. Phys. Math. 1 (2011) 195-198.

[6] C. Scott, B. Remy, J.-L. Collet, A. Cael, C. Bao, F. Danoix, B. Malard, C. Curfs, Precipitation strengthening in high manganese austenitic TWIP steels, Int. J. Mater. Res. 102 (5) (2011) 538-549.

[7] C. Haase, C. Zehnder, T. Ingendahl, A. Bikar, F. Tang, B. Hallstedt, W. Hu, W. Bleck, D.A. Molodov, On the deformation behavior of $\kappa$-carbide-free and $\kappa$-carbide-containing high-Mn light-weight steel, Acta Mater. 122 (2017) 332-343.

[8] R. Ueji, N. Tsuchida, D. Terada, N. Tsuji, Y. Tanaka, A. Takemura, K. Kunishige, Tensile properties and twinning behavior of high manganese austenitic steel with fine-grained structure, Scr. Mater. 59 (2008) 963-966.

[9] R. Saha, R. Ueji, N. Tsuji, Fully recrystallized nanostructure fabricated without severe plastic deformation in high-Mn austenitic steel, Scr. Mater. 68 (2013) 813-816.

[10] P.S. Kusakin, R.O. Kaibyshev, High-Mn twinning-induced plasticity steels: microstructure and mechanical properties, Rev. Adv. Mater. Sci. 44 (2016) 326-360.

[11] C. Haase, L.A. Barrales-Mora, D.A. Molodov, G. Gottstein, Tailoring the mechanical properties of a twinning-induced plasticity steel by retention of deformation twins during heat treatment, Metall. Mater. Trans. A 44 (2013) 4445-4449.

[12] C. Haase, L.A. Barrales-Mora, F. Roters, D.A. Molodov, G. Gottstein, Applying the texture analysis for optimizing thermomechanical treatment of high manganese twinning-induced plasticity steel, Acta Mater. 80 (2014) 327-340.

[13] C. Haase, T. Ingendahl, O. Güvenç, M. Bambach, W. Bleck, D.A. Molodov, L.A. Barrales-Mora, On the applicability of recovery-annealed twinning-induced plasticity steels: potential and limitations, Mater. Sci. Eng. A 649 (2016) 74-84.

[14] I.B. Timokhina, A. Medvedev, R. Lapovok, Severe plastic deformation of a TWIP steel, Mater. Sci. Eng. A 593 (2014) 163-169.

[15] C. Haase, O. Kremer, W. Hu, T. Ingendahl, R. Lapovok, D.A. Molodov, Equalchannel angular pressing and annealing of a twinning-induced plasticity steel: microstructure, texture, and mechanical properties, Acta Mater. 107 (2016) 239-253.

[16] S.V. Zherebtsov, G.S. Dyakonov, A.A. Salem, V.I. Sokolenko, G.A. Salishchev, S.L. Semiatin, Acta Mater. 61 (2013) 1167-1178.

[17] M. Klimova, G. Dyakonov, S. Zherebtsov, G. Salishchev, D. Molodov, Twinning induced nanostructure formation during cryo-deformation, IOP Conf. Series: Mater. Sci. Eng. 63 (2014) 012157.

[18] J. Hirsch, K. Lücke, Mechanism of deformation and development of rolling textures in polycrystalline F.C.C. metals - I. Description of rolling texture development in homogeneous CuZn alloys, Acta Metall. 36 (1988) 2863-2882.

[19] S. Vercammen, B. Blanpain, B.C. De Cooman, P. Wollants, Cold rolling behaviour of an austenitic Fe-30Mn-3Al-3Si TWIP-steel: the importance of deformation twinning, Acta Mater. 52 (2004) 2005-2012.

[20] E. El-Danaf, S.R. Kalidindi, R.D. Doherty, C. Necker, Deformation texture transition in brass, critical role of micro-scale shear bands, Acta Mater. 48 (2000) 2665-2673.

[21] D.B. Williams, C.B. Carter, Transmission Electron Microscopy, Plenum Press, New York, 1996.

[22] R.K. Ham, N.G. Sharpe, Philos. Mag. 6 (1961) 1193.

[23] P.B. Hirsch, Electron Microscopy of Thin Crystals, (1968).

[24] R. Hielscher, H. Schaeben, A novel pole figure inversion method: specification of the MTEX algorithm, J. Appl. Crystallogr. 41 (2008) 1024-1037.

[25] F. Bachmann, R. Hielscher, H. Schaeben, Texture analysis with MTEX - free and open source software toolbox, Solid State Phenom. 160 (2010) 63-68.

[26] G. Will, Powder Diffraction: The Rietveld Method and the Two-stage Method to Determine and Refine Crystal Structures From Powder Diffraction Data, Springer, Berlin, 2005.

[27] A. Saeed-Akbari, L. Mosecker, A. Schwedt, W. Bleck, Characterization and prediction of flow behavior in high-manganese twinning induced plasticity steels: part I Mechanism maps and work-hardening behaviour, Metall. Mater. Trans. A 43 (2011) 
1688-1704.

[28] A. Saeed-Akbari, J. Imlau, U. Prahl, W. Bleck, Derivation and variation in composition-dependent stacking fault energy maps based on subregular solution model in high-manganese steels, Metall. Mater. Trans. A 40 (2009) 3076-3090.

[29] S. Huang, W. Li, S. Lu, F. Tian, J. Shen, E. Holmström, L. Vitos, Temperature dependent stacking fault energy of FeCrCoNiMn high entropy alloy, Scr. Mater. 108 (2015) 44-47.

[30] J.A. Venables, The martensite transformation in stainless steel, Philos. Mag. 7 (73) (1962) 35-44

[31] G.B. Olson, M. Azrin, Transformation behavior of TRIP steels, Metall. Trans. A. 9A (1978) 713-721.

[32] S.L. Wong, M. Madivala, U. Prahl, F. Roters, D. Raabe, A crystal plasticity model for twinning- and transformation-induced plasticity, Acta Mater. 118 (2016) 140-151.

[33] Y. Lü, D.A. Molodov, G. Gottstein, Correlation between microstructure and texture development in a cold-rolled TWIP steel, ISIJ Int. 51 (2011) 812-817.

[34] C. Haase, S.G. Chowdhury, L.A. Barrales-Mora, D.A. Molodov, G. Gottstein, On the relation of microstructure and texture evolution in an austenitic Fe-28Mn-0.28C TWIP steel during cold rolling, Metall. Mater. Trans. A 44 (2013) 911-922.

[35] A.A. Saleh, C. Haase, E.V. Pereloma, D.A. Molodov, A.A. Gazder, On the evolution and modelling of brass-type texture in cold-rolled twinning-induced plasticity steel, Acta Mater. 70 (2014) 259-271.

[36] Z. Yanushkevich, A. Belyakov, C. Haase, D.A. Molodov, R. Kaibyshev, Structural/ textural changes and strengthening of an advanced high-Mn steel subjected to cold rolling, Mater. Sci. Eng. A 651 (2016) 763-773.

[37] P. Kusakin, A. Belyakov, C. Haase, R. Kaibyshev, D.A. Molodov, Microstructure evolution and strengthening mechanisms of Fe-23Mn-0.3C-1.5Al TWIP steel during cold rolling, Mater. Sci. Eng. A 617 (2014) 52-60. 